Joseph Lo Bianco

\title{
Dialogue between ELF and the field of language policy and planning
}

Abstract: This paper explores the relevance of concepts and methods of language planning and policy for ELF researchers and teachers. As the global communication environment consolidates through globalisation of systems, such as publishing and education credentialing, the topics chosen for research and even some practices in teaching can be seen as forms of intervention which influence form, usage, and status of languages and language varieties. The escalating role of English in the public life of more and more countries raises questions of the overall language ecology (how English interacts with other languages in existing and future communication environments). By fostering dialogue with the conceptual categories and methods of language planning, ELF scholars and practitioners can sharpen their focus on how institutional and publishing gatekeepers operate and foster an expanded sense of what English as an international language can mean, in the interests of encouraging a more democratised global communication order.

Keywords: language policy, language planning through policy, language planning through cultivation, language problems, ELF aims, universal multilingualism, democratising world communication

Joseph Lo Bianco: Melbourne Graduate School of Education, University of Melbourne Australia. E-mail: j.lobianco@unimelb.edu.au

\section{Introduction}

Challenges confronting ELF and likely future developments as expressed in its now extensive literature have been posed principally around conceptualisation, description, and pedagogy. Each of these nodes of ELF activity will continue to be refined and will evolve as new national and institutional settings arise in which ELF is present and as debate, research, and reflection on the role of English in the public life of more and more countries intensifies.

My concern here is with the interaction between ELF, however conceptualised, described or taught, and in whatever settings it is debated, and the distinctive field of LPP, i.e., language policy and planning. LPP divides into two distinct practices: theoretical or descriptive analysis of efforts to direct the course of 
language developments by deliberate intervention, and the applied work of real world policy making on communication problems.

As neither a researcher into English nor an English teacher, though I have been both at different times in the past, I approach ELF from both of these perspectives: as an LPP analyst but also as an LPP practitioner. This paper is derived from a presentation at The Sixth Conference of English as a Lingua Franca (ELF 6) in Rome (though for me it was ELF 1), on 6 September 2013, the preceding large body of conferencing suggesting that my comments join an already deep and fast flowing stream of conceptualisation, description, and pedagogy, and run the risk of not connecting sufficiently well with ELF 1-5.

What can the two dimensions of LPP contribute to ELF scholarship and English language teaching? We can discuss this in ascending orders of relevance. First, I assume, minimally, that ELF scholars and teachers can be spoken of in a more or less unitary way, taking for granted that they have common interest in advancing recognition of ELF as a legitimate field of academic research, second, that ELF scholars are collectively committed to contesting institutional discrimination against speakers of English as a Lingua Franca, especially students, and maximally that the ELF community are seeking inclusion of ELF in programs of teaching and research. Essentially these are all claims for non-stigmatisation of ELF speakers and their variable use of English, based on research evidence of its validity and inevitability, i.e., its legitimate claim to institutional presence based on its sociolinguistic existence. Expressed in these ways ELF practitioners, researchers or teachers, are linked directly to the purposes of LPP which then have whether they are a direct bearing on the concerns of the ELF professional community (Cogo and Jenkins 2010; Dewey and Jenkins 2010; Mauranen 2011; Seidlhofer 2012).

The formulation used above relies on the major assumption (Lo Bianco 2010) of what has been called the classical period of LPP, which is that LPP is all the research and intervention that flows from an authoritative person or agency deciding that there exists a language problem which needs to be resolved. For most of its modern conceptual history, language planning involved assisting the governments, usually through education ministries, in developing post-colonial settings in Africa and Asia to address pressing questions of medium of instruction, or assisting cultural agencies to expand the terminological range of a language, or a community of indigenous people to select, codify, and disseminate an orthographic system for a local language. Common to all of these is the assumption that LPP is what proceeds from an established communication problem, usually identified by public authorities, which engage the expertise of professional language planners to conduct research into the characteristics of the nominated language problem and propose solutions. 
In this phase of its life LPP sought to emulate the general policy sciences, transferring into questions of language policy making methods, assumptions, and approaches that could equally be applied to medical, infrastructure, or macroeconomic policy making. Some language planning today is conducted following more or less these managerial frameworks but the concerns addressed, the agencies and entities undertaking LPP, the processes and methods applied, and most importantly the conceptual frameworks underpinning the field, have expanded greatly, have become more wide-ranging and both self- and socially critical.

The classical form of LPP was subjected to strong critique and rejection during the 1990s and in the past two decades has undergone an impressive resurgence. Today there is lively theoretical replenishment resulting in new journals, professional training programs, a large increase in $\mathrm{PhD}$ level research, a great spike in book-length academic treatments, a vast expansion in the number and range of agencies commissioning LPP research input, and a healthy and robust refinement of the more problematic aspects of LPP work, such as the interests, subjectivity, and purposes of its practitioners (Lo Bianco 2004, 2010).

\section{ELF and LPP}

The theory of problems was a key part of the classical paradigm subjected to criticism, exposing the reality that the uncritical idea of taken for granted and preexisting language problems decided by official agencies of government was an objectivist cover for projects of repression for minority groups, neo-colonial projects of subjugation, occupational channelling for immigrants, or statist nationing and political consolidation in the interest of elites. These criticisms forced LPP scholars to examine the assumptions of the field revealing the constructed and interested nature of the idea of language problems, and stimulated a search for innovation. Key among the new practices of the field are more democratically and discursively oriented approaches to determining what language problems are, involving deliberations and citizen action in conjunction with academic experts, teachers, and official representatives. Collaborative processes of this kind are still uncommon in practice, but they represent the beginnings of a new phase of language planning work in which new ways to understand the scope and process of planning and even of language itself form part of LPP.

A classical definition of the field of LPP scholarship, referencing the practice more than the analysis of the phenomenon, is Robert Cooper's (1989: 45) succinct statement that LPP consists of "[. . . ] deliberate efforts to influence the behavior of others with respect to the acquisition, structure, or functional allocation of their language codes." 
Contemporary definitions have greatly expanded this remit to allow space for subjective perspectives of language users, a wider scope for the ultimate aims, beyond single language codes, to include attention to the entire language ecology of a site, such as a school or university, a sector, such as the entire education system, or health and legal services, and an entire field of interacting language practices, such as might be included within an economy, a nation state and its institutions. New space is provided for critical and democratic determination of the scope and aim of language planning projects and of the methods and consequences of intervention.

It follows from this that potential interaction between ELF and the academic sub-discipline of LPP, which is still finding its academic feet, commences from ELF's sense of what communication issues or problems it wishes to intervene in, to shape and influence. ELF projects of “description” might be included, but possibly LPP and ELF come together most around pedagogy, and other kinds of application, but also conceptualisation, since this activity, and even description, involve motivated choices from all the kinds of concepts and descriptions that are possible to those that are preferred. In whichever way ELF problems are defined for LPP, and by whomever they are defined, ELF can look to newly vigorous practices of LPP that are applicable in single sites, such as a school, university, hospital, or airport, factory, or immigration servicing department of a government. ELF can look to LPP in relation to desirable change for an entire sector to which these single sites might belong. ELF can look to LPP in relation to the complete political jurisdiction in which the sites and the sectors are located.

In all of these sites, sectors, and fields there are gatekeepers of standards, appliers of rules, interpreters of performance, publishers of texts making choices about permissible forms of expression, and others who both formally and informally police explicit and implicit rules. Sometimes, more conspiratorially, such rules are not so much implied or made explicit but seem better described as overt and covert. This move from implicit/explicit to overt/covert tends to rely on whether we see linguistic rules being more or less neutral of the interests of speakers, whether the interests are cultural, economic, ideological, or political. Once we imagine that interests might play a role, we enter the realm of the more political end of LPP, and begin to depart from its applied linguistics genesis which tends to stress descriptive accounts of instances of language problem solving, rather than socially and ideologically critical accounts of LPP activity in the real world of decision making, government, and administration in which linguistic behaviours are of course always present.

If researchers of ELF are seeking not just enhanced academic acknowledgement of English as it is used as a lingua franca, though my argument applies in that case as well, but recognition of speakers of ELF and removal of discrimin- 
ation against them, then ELF and LPP share direct and immediate overlap. This would justify a considered effort of dialogue between the two areas of applied language work and might produce a productive outcome for ELF, allowing it to draw on the repository of experiences and understandings of LPP to critique attitudes and policies toward ELF speakers and ELF research. This work would benefit LPP as well since the subtle cultural and scholarly challenge that global English and particularly English used as a Lingua Franca pose, what kind of English this is, would force more LPP scholars to sharpen attention to "intra" language global communication planning, which remains a relatively neglected area in language planning theory.

\section{Innovation and change}

ELF also links to LPP through the wider interest of English language educators in innovation and change to improve learning outcomes. The extent that these are influenced by rules, whether implicit or declared, and by formal policies of different agencies, are obvious cases for this link. However this link between ELF and LPP through general English language education also comes about because a great deal of innovation and change in English language education originates within society, economy, and politics, and takes the form of media-based demands for more English medium education and for more effective English teaching outcomes.

If we document these we see right away that these considerations involve different parts of the world, the different language ecologies involved in these settings, the histories of relation between English and local languages in those settings, the favoured practices of foreign language teaching and therefore of English teaching in such settings, and the policy making traditions and styles these settings use. To make this more concrete we can compare the different trajectories towards widespread English teaching and learning in China and Malaysia.

The latter has a long history of English-replacement LPP, favouring Malay medium education from primary to university education, with concessions permitted to vernacular schools run by the large Chinese and Indian (mostly Tamil) language communities. In 2002 the then Prime Minister Mahathir Mohammad announced the policy of Teaching Mathematics, Technology and Science in English (PPSMI, in its Malay acronym) commencing in 2003. This was a declarative top-down kind of language policy making, with the immediate effect of rupturing the longstanding national project of replacing English with Bahasa Melayu (BM).

The project launched by Mahathir, which aimed to do no less than reorganise the communicative matrix of the nation, was hampered from achieving its effects 
because the state and BM interests share political power with minority language interests, for whom both English and BM have different value depending on their interaction with each other and internally.

The wider communication ecology hinted at here is a major influence today on LPP theory since, to paraphrase Cooper, deliberate efforts to influence linguistic behaviours of others cannot be unidirectional, and the actors who seek to direct these changes are constrained by the countervailing power of other speech communities and their political interests. Minorities disadvantaged under colonial English language regimes were differentially disadvantaged as they would prove to be under the replacing BM regime. Into this mix of sub-national and national communication politics, the later impact of full-blown economic globalisation and its English-favouring effects disrupted the nation's BM project since English returned for consideration, as it were, no longer in colonial language guise but as the medium of competitive economic globalisation.

From the late 1990s many Malaysian business concerns pressed the government to moderate the BM policy to foster English-skilled labour market access and the international portability of domestic qualifications. It was to this extranational source of pressure that Dr Mahathir responded with the PPSMI innovation. In his own account of the change he stated that pragmatic acceptance of the domination of world business, and also science publishing and technology, by English required a move away from "nationalism" to ensure Malaysians were not "working as servants to others" (cited in Gill 2007).

Had the PPSMI project been informed by an LPP sensitive to the power of the pre-existing communication-ecology it would have addressed English in both its localised, named varieties, with all their internal differentiation, either operating endo-normatively or in a mixed mode, or present transactionally as ELF, a role English shares to a greater or lesser degree with Indonesian/Malay and Chinese. It would also have addressed the primary educational socialisation of a large percentage of the population in many small tribal and ethnic languages. Failure to negotiate the aims and conduct the processes of the PPSMI project in these ways rendered it vulnerable ideologically and sociolinguistically. However, PPSMI was ultimately abandoned due to the immense dislocation its (hasty and unplanned) implementation had caused but the politically controversial nature and the communicatively naïve representation were strong contributing factors. Both practical reasons and various symbolic ones are considerations that more nuanced LPP takes into consideration in accounting for instances of language planning.

Because the policy was not moderated and checked against the stocks of information, ideologies, and interests of researchers, practitioners, and various interest groups (Weiss 1983), it was a weak form of general policy making even in classical policy-making frameworks. That it was also not informed by concepts, 
models, and analysis from the stock of experience accumulated within LPP in recent decades rendered it especially weak as a project of willed communication change by the state. A language ecology model would have insisted on close documentation of the entire sociolinguistic matrix of the multilingual environment, and what realistic communication aims could be set against current communication realities and future imagined ones. Because poor conceptualisation compounded the insurmountable obstacle of impractical delivery and political opposition, the policy was unsustainable and from 2012 BM was restored as medium of instruction in the nominated subjects.

Although PPSMI is not a direct parallel of specific ELF concerns, it serves to highlight the scope of analytical interests contained within modern LPP and to underscore how global English education expansion projects must always be conducted in light of and sensitive to their surrounding communicative contexts. The ELF implication is that if political planners cannot quarantine favoured and high-profile decisions from the enveloping communicative context in which they are applied, neither can teachers and researchers, even in specific domains where teachers and researchers might imagine themselves to have more traction. Here we can consider what Dewey, speaking at ELF 6 in Rome, called "privilege bias" in ELF pedagogy, suggesting a further way in which LPP is relevant to ELF work.

\section{Privilege, power, and keeping gates}

Whilst privilege has its site-specific realities, such as how in a school or college privilege markers in communication become established, how hierarchies of regard are organised and distributed, privilege bias is constituted in the alignment of in-school communication hierarchies and the kinds of capital they allow a speaker to claim in the wider economy and society. Out-of-school social and political realities, as expressed in norms and forms of communication, expose disparities in social opportunity. Essentially this is because acquisition of prestige forms of speech and literacy are shaped by the social networks available to and inhabited by learners. Social stratification corresponds with communicative stratification in mutually constitutive processes: the distribution of opportunity being mediated by communication, the models of powerful and power-conferring communication modes, accents, vocabulary items, phrases, styles of expression, nuance, and suggestion. This entire repertoire of communicative cultural capital is distributed differentially because it is imparted in the practices of social life rather than explicitly taught in public education. Overturning bias that accrues to speakers of prestige forms and is denied to speakers of stigmatised forms cannot 
be an enterprise that teachers and researchers alone could achieve. LPP here is a potential dialogue partner for ELF scholars concerned with such matters in relation to prejudice against norms of ELF practice.

Prestige planning is a long-established practice of LPP analysis. Here Cooper's requirement that LPP needs to be "deliberate" is a serious obstacle. In reality processes of language change can be analysed along a continuum, marked by deliberate and accidental change at the extreme ends. Even deliberate language change can be pursued via approaches that are highly conscious, such as in public policy, or processes that rely on cultural cultivation of such change. The latter function through the socially inculcated establishment of esteem and prestige and aim to attach privilege to select linguistic codes in preference to and in rejection of specific others. Usually the time frame within which cultivation-based prestige planning operates is vast. Perhaps the most readily and classically identifiable instance is Dante Alighieri's efforts to attach prestige to vernacular expression over Latin in fourteenth-century Italy (Lo Bianco 2005). Dante's case is unique and instructive because he was both a theoretician of language-planning change and a practitioner. In his 1304-1308 theory of the prestige and power of vernaculars, De Vulgari Eloquentia (DVE), he proposed the construction of an artificial language, and offered a range of specific criteria against which this construction would occur. While DVE is most often read as a treatise on poetics, and ignored by many LPP scholars, it is in fact a handbook on language invention with precise and explicit purposes, criteria, and methods. The aim was to produce a language to mediate between Latin and local dialects, with the express purpose of facilitating invention of a court, a corresponding state, and a national community. The book is unfinished because Dante abandons his theorising and writes the Comedy, later dubbed Divine, in precisely the code whose invention he was advocating in DVE.

While it took more than 650 years for the nation and some 730 years for the language to fully emerge, the linguistic code he proposed and helped invent came to fruition specifically through the process of prestige/esteem planning. We can see in the lineaments of this story multiple other cases of this kind, where powerful effects of literary, or discursive, or other kinds of modelling language planning end up shaping deep change in social and political life. Literary canons have been central to the establishment of prestige, often in relation to rival dialects or varieties rather than different languages, and this makes some of their historical trajectory relevant to ELF in the twenty-first century, enriched by the additional communicative tools of social media. However anti-prestige forms of speech or talk, or writing, whether by criminal gangs, or musicians, rappers, and street talkers, all serve to show that persuasive performative language can subversively and transgressively undermine negative status attributions. These kinds of en- 
acted, discursive, or performed LPP processes achieve the undermining of prevailing frameworks by transferring prestige, formally or in dissident action, to new attachments that their adherents desire.

Changing the practices and habits of literary, publishing, examination, and teaching gatekeepers requires action at both the explicit "policy" level of LPP and the more diffused but critically important "cultivation" or performative level. The kinds of actions envisaged here aim to attract new kinds of prestige that contest established ones, or that expose their weaknesses, injustices, or redundancies. In formal education "gatekeepers" operate with power in relation to people who trade in knowledge, the oldest dualism in public policy theory, present in western considerations since Plato's republic. If we conceive the "polis" not as a political republic but as the community of practice of ELF, we can imagine what kinds of action might ensue if it were to engage in a productive dialogue with LPP. Policy texts tend to be issued by people in authority, able to disperse funding, hire and fire teachers, authorise curricula, set up examinations or assessments. Formal authority of this kind produces texts of direction, and gatekeepers in my understanding of this term serve this authority by guarding that its rules and regulations are adhered to. In this reasoning, gatekeepers might be less important than what some ELF researchers and practitioners appear to believe and changing attitudes towards ELF and ELF speakers might be better advocated by participating in wider cultural politics, such as envisaged by the "cultivation" arm of LPP, than in contesting the implementing the power of gatekeepers.

One aim of ELF scholars can be represented as "democratising" what counts as English, and especially what counts as acceptable English. The work of spoken corpus construction and analysis plays a vital role in this, to establish the separate existence, viability, and scientific vitality of ELF. Claims to the legitimacy of this and its appropriateness in sites, sectors, and fields of action, such as schools, education systems, and institutions, can flow best with systematic documentation of ELF. To position ELF advocates with strategic knowledge, however, suggests activity is needed in the realm of culture, popular and elite, and in the policy and politics realms usually focused on in LPP.

\section{Obeying in advance}

Much of the appeal of ELF researchers is to educators, who are increasingly called upon to incorporate new notions of variability in English, highlighted in ELF research (Seidlhofer 2011). The large corpora of spoken and written text samples support its claim to be a legitimate use of language in its own right but its communicative and sociolinguistic presence poses unfamiliar challenges for 
teaching. To what extent are teachers, or more broadly, educators "sovereign" or sufficiently autonomous that they can independently heed this call? This is essentially what the designers of the failed PPSMI initiative failed to consider, the ecology of communication into which their radical experiment would be located. A language ecology focused LPP would stress communicative inseparability between educator, expert, policy maker, environment, economy, and society, a framework which suggests a series of strategies and directions for ELF to consider.

Discussing academic publishing, Seidlhofer (2012) introduces the German term vorauseilender Gehorsam, translated as 'pre-emptive obedience', in which individuals or even whole groups of people anticipate behaviours of powerful others and submissively adapt to what they believe is expected of them, to explain aspects of the refusal of publishers to acknowledge actually occurring variable uses of English. This continues a suggestive thread linking Jennifer Jenkins's (2009) argument that it is various gatekeepers who inhibit responsiveness of institutions to ELF and Martin Dewey's (2012) identification of privilege bias with many calls made by ELF researchers directly to teachers. If various actors in networks of language education, such as academic publishing, are complying with "presupposed expectations" against more inclusive and fair notions of what counts as acceptable English, who generates these expectations? How are they formulated as language norms? Who has formulated them and with what purposes, and under what circumstances? How are the norms communicated to others who are required to either follow models or, if they cannot, to accept a lower hierarchy in the linguistic pecking order?

In Seidlhofer's discussion, vorauseilender Gehorsam is applied to the large and commercially motivated field of academic and more specifically scientific publishing in English, posing the question of how such publishing could be democratised, this word expressing a central desideratum in ELF writings. In language policy terms this constitutes a classic problem. As implied above, in its earliest incarnation the "science" of LPP emulated the practices and procedures of the general policy sciences in which the first task of any language planning project was devoted to the rationalist, formal, and managerial preoccupation with problem definition. Various procedures of problem definition assisted professional policy makers to understand the scope and limits of the policy challenge, but also to depict its character. Problems were initially divided into tame and wicked, the former offering policy makers easy traction because they were relatively simple and mostly technical in nature, the latter complex and/or ideologically laden, and therefore with low policy traction. Problem definition also aimed to depict the various dimensions, duration, and vitality of the problem to be tackled with policy analysis and policy making. 
Keeping this in mind we can see the problem of academic English vorauseilender Gehorsam as a curate's egg: some parts tame, others wicked. A tame policy problem is amenable to conventional policy work (cost benefit analyses, alternative scenario depiction, monetisation, etc.), is fast and straightforward and requires little need of public legitimation. More complex or wicked problems involve multiple actors operating in a diffuse way, rather like the competitive market of academic publishing.

\section{Who can act to change the communication order?}

Independent action, for example, by one publishing house, or a single journal or an individual editor, to democratise English writing practices by reducing native speaker imposition of their English norms would leave the agent of such change vulnerable to financial loss and erosion of market share. If I understand vorauseilender Gehorsam correctly it seems that LPP in scientific publishing runs the risk of failure because of the ambiguous effects of its operations, because all actors have very similar expectations, and breaking away would require great strength and conviction, financial resources sufficient to cushion temporary losses, and a strong motivation to take such risks.

However, while the presupposed expectations contained in vorauseilender Gehorsam operate prospectively, i.e., obedience is offered in anticipation, thereby relieving power holders of the need to impose obedience coercively, those expectations are the product of past coercion or at least the exercise of direct power. Historical policies, whether overt or covertly achieved, produced the current norms and expectations, and are policed through the practice identified by Seidlhofer. If academic publishing is impervious to policy action because the risks in the competitive commercial market are too great, academic publishing practice may not be immune to change through the cultivation branch of LPP activity.

Cultivation LPP, as the Dante case shows, is slow-acting, needs to accumulate supporters from diverse interests over time, relies on a process of transferring new practices from elites to wider strata of society, and legitimises itself through its essentially democratic claims, that is by steadily expanding the number of beneficiaries. Cultural leadership is the principal mechanism of social change and discursive re-framing of the assumptions that buttress the behaviour we are trying to change is the main mode of reconceptualising the language policy problem. 
Democratising academic discourse (Mauranen 2011, 2012) involves destabilising the privilege bias which is bound up with the power of a particular variety of English. In effect this is another face of the same phenomenon, since while privilege is the reward for power, rather than power itself, universities embody the operations of cultural capital, and give effect to a now global marketplace for production and exchange of competence and certificated expertise. Privilege is a currency of this exchange; and merges with market power. In effect, then, to contest the privilege and therefore power of particular varieties of English operating with norms that discriminate unfairly against good scientists because their English isn't native, and by extension good science because it isn't produced by English native speakers, cultivation-based culturally focused LPP is the most promising course of action.

\section{China's choices}

Both the power and the privileges of English will be influenced to a considerable degree by the language planning and policy choices of China. English, once excoriated as "barbarian" (Adamson 2002), is now compulsorily studied by hundreds of millions of people, and forms an expected, normal, and natural part of education in China, at school and university level. This radical transformation in the status of English is product of LPP of the two main kinds I have been discussing, overt policy and cultural cultivation, the former imposing rules and expectations, the latter re-framing the cultural meanings and personal worth of English for tens of millions of learners (Lo Bianco et al. 2009).

This transformation has allocated English the status of a career-enhancing compulsory basic skill rather than an elective foreign language, converting it from a subject for the few to a hurdle for the many. As a result, passing the College English Test produces extreme stress leading to "cramming for China's annual college-entrance exam, some [...] hooked up to oxygen canisters and intravenous drips of amino acids during late-night and weekend study marathons. $[\mathrm{P}]$ arents hire special tutors, force the kids into educational boot camps in the summer and promise lavish gifts of cash and cars for good results. Housekeepers and nannies with college degrees come at a huge premium [...] Commercial and military flights [... . rerouted to limit overhead noise [...] Roads to exam venues are blocked off [...] honking is prohibited and taxi rides are free" (McDonald 2012).

The fields of LPP and ELF are challenged to comprehend such phenomena, and the underlying economic globalization which produces such mass cramming 
challenges sociolinguistics in its entirety (Blommaert 2010). The tools and categories developed by LPP originate within the political "container" of the national state, and the policy activity of cultivation and consolidation of national languages, the teaching and acquisition of additional ones, the accommodation of minorities, etc. Yet, the rapidity of the expansion of world languages, and preeminently of English, impose a new container, or an absence of a container, certainly they weaken the national container which has given rise to the context in which all languages are understood. English as a Lingua Franca, after all, still centrally names its place of origin, a political and cultural state distant from China. Explaining this "domestication" of the formerly foreign calls for expanding concepts and categories of analysis, along with revisiting basic assumptions of how language change occurs and how new forms of talk arise in the fluid new worlds that we can see but not yet fully comprehend. The analytical categories for comprehending society/language relations which lie at the heart of sociolinguistics are exposed as having serious limitations (Blommaert 2010; Seidlhofer 2011) when addressing the massive and mass mobility of the contemporary world, in which specific places and social categories correspond to each other in stable mostly resident communities.

Chinese traditional representations of foreign language learning made use of a distinction between utility and essence as a way to foster foreign language study while distancing its cultural effects. Western learning was seen to offer practical application and short-term benefit, while Chinese learning was seen to inculcate moral principles, order, stability, continuation, rootedness, and belonging (Gao 2009). Gao's multi-year China-wide examination of this phenomenon leads her to conclude that "[f] or the Chinese, the ti-yong dilemma, the recurrent themes of a clash between $t i$, and ambivalent attitudes toward English are deeply rooted in history and have formed a psychological complex transmitted down through generations. Current and future generations of Chinese language policy makers, educators, and learners are destined to struggle for creative solutions to this persistent identity dilemma" (2009: 75).

In this depiction Gao joins ELF and LPP in the enterprise of understanding the directions and nature of the Chinese embrace of English, the requirement of struggling for "creative solutions" underscores that the terrain of language policy and planning is the very practical one of resolving language problems. Among the creative solutions would be a move away from current representations of English in Chinese pedagogy where it is mostly conceived as a singular, correctness-focused, native speaker oriented, monolithic entity. Some of the stress involved in cramming would be alleviated if a new conception of contemporary English as a contextually variable global means of communication were infused into Chinese English pedagogy. Injecting this sociolinguistic insight into 
Chinese language planning for English acquisition would also serve to mitigate the persisting association of cultural ownership of English by its old native speaker centres.

That none of the immense stress of cramming and failure is inexorable is underscored in an article published on Monday, 21 October 2013 in the South China Morning Post, entitled "Debate rages as China seeks to reduce emphasis on English language education," in the main English language newspaper in Hong Kong. In an article adorned with predictable photographs of cramming students, but ominously with the subtle character of disapproval, reporter Chris Luo, writes:

Education reforms seeking to reduce the emphasis on English in college entrance exams have sparked debate online. Starting from 2016, Beijing authorities will reduce the 150-point English examination in college entrance exams to 100 points, while at the same time raising the number of points attributed to Chinese and mathematics, the affiliated website of China's Communist Party newspaper Guangming Daily reported on Monday [... . [T]he proposal also suggested the removal of English entirely from the curriculum before grade three [...] Online comments on news portal Sina.com showed an overwhelmingly positive response from online users - many of whom appeared to be parents of students [.. .] [Others] went further calling for English examinations to be phased out of college entrance exams entirely.

\section{Concluding remarks}

The central role played by English in globalisation is accompanied by the vastly unequal contributions to the global communication effort required of global citizens. This is apparent in the contrasting fortunes of social bilingualism. We see a continuing crisis of second and foreign language enrolments in Englishspeaking countries, where sustaining viable school and university programs in even quite large languages has become difficult and governments engage in constant promotion to attract students to language study. Meanwhile more and more non-English speaking countries, professions, and activities impose knowledge of English as the criterion of participation in general education, and parents and students engage in vorauseilender Gehorsam obeying the dictates of a future world communication order in which it is presumed major disadvantages will attend those who do not conform to what authority has determined it means to "know English".

English increasingly operates sociologically as a hurdle of membership as much as a communicative medium. Even in domains of life where English is not practically needed, such as in many professions and trades, courses and pro- 
grams of study in China, its study is imposed by education administrators as a proxy for processes of selection and grading. This imposition is then made doubly difficult by restricted and increasingly redundant understandings of what English is, denying many students access to the resources of English which an ELFinformed approach would offer.

In communication ecology this sprawling endeavour of language policy and planning involves all languages in the slipstream of producing an ever more closely tied global economy, education system, and cultural milieu. By opting out of serious effort to acquire high levels of second language proficiency, native English speakers are transferring the burden of facilitating international communication to non-native speakers of English. This raises the prospect of a communicative bifurcation in which ELF speakers will communicate within environments and contexts of shared and assumed multilingualism, but these will not be shared with ever growing numbers of norm-setting and policing English native speakers who will communicate in multilingual environments and contexts as monolinguals. In abrogating their obligations to collectively forge a fairer communication order, native speakers of English will be forced to concede space to non-native English speakers, this space will be the political enfranchisement of non-native speakers to establish legitimacy for various preferred forms of ELF, an influence which will surely grow and even determine the particulars of the communication regime which will have ELF at its centre.

A democratised global communication order will involve a great deal more than English, since English is not now and is unlikely ever to be the sole lingua franca in the world. However, as the current and for the foreseeable future the main element in the world's shared talk and writing, English itself cannot remain immune from the needs and interests of its majority users. ELF practitioners and researchers should establish the aim of fostering universal multilingualism as a critical objective towards a fairer communication order for the future. This can serve as a proper accompaniment to the equally legitimate consequence of research and teaching on English in the world which demands that its new forms and norms be recognised as the product and need of the identities and purposes of its new users.

\section{References}

Adamson, Bob. 2002. Barbarian as a foreign language. World Englishes 21(2). 231-243. Blommaert, Jan. 2010. The sociolinguistics of globalization. Cambridge: Cambridge University Press. 
Cogo, Alessia \& Jennifer Jenkins. 2010. English as a Lingua Franca in Europe: A mismatch between policy and practice. European Journal of Language Policy 2(2). 271-294.

Cooper, Robert. 1989. Language planning and social change. Cambridge: Cambridge University Press.

Dewey, Martin. 2012. Towards a post-normative approach: Learning the pedagogy of ELF. Journal of English as a Lingua Franca 1(1). 141-170.

Dewey, Martin \& Jennifer Jenkins. 2010. English as a Lingua Franca in the global context: Interconnectedness, variation and change. In Mukul Saxena \& Tope Omoniyi (eds), Contending with globalization in World Englishes, 72-86. Bristol: Multilingual Matters.

Gao, Yihong. 2009. Sociocultural contexts and English in China: Retaining and reforming the Cultural Habitus. In Joseph Lo Bianco, Jane Orton \& Gao Yihong (eds), China and English: Globalisation and dilemmas of identity, 56-78. Clevedon: Multilingual Matters.

Gill, Saran Kaur. 2007. Shift in language in policy in Malaysia. AILA Review 20. 106-122. Jenkins, Jennifer. 2009. English as a Lingua Franca: Interpretations and attitudes. World Englishes 28(2). 200-207.

Lo Bianco, Joseph. 2004. Language planning as applied linguistics. In Alan Davies \& Catherine Elder (eds), Handbook of applied linguistics, 738-763. Blackwell: London.

Lo Bianco, Joseph. 2005. Globalisation and national communities of communication. Language Problems and Language Planning 29(2). 109-135.

Lo Bianco, Joseph. 2010. Language policy and planning. In Nancy H. Hornberger \& Sandra Lee McKay (eds), Sociolinguistics and Language Education, 143-176. Bristol: Multilingual Matters.

Lo Bianco, Joseph, Jane Orton \& Gao Yihong (eds). 2009. China and English: Globalisation and dilemmas of identity. Clevedon: Multilingual Matters.

Luo, Chris. 2013. Debate rages as China seeks to reduce emphasis on English language education. South China Morning Post 21 October. http://www.scmp.com/news/chinainsider/article/1336698/debate-rages-china-seeks-reduce-emphasis-english-language (accessed 11 November 2013).

Mauranen, Anna. 2011. English as the lingua franca of the academic world. In Brian Paltridge, Diane Belcher \& Ann Johns (eds), New directions in English for specific purposes research, 94-117. Ann Arbor: University of Michigan Press.

Mauranen, Anna. 2012, Exploring ELF: Academic English shaped by non-native speakers. Cambridge: Cambridge University Press.

McDonald, Mark. 2012. Putting Chinese students to the test. International Herald Tribune 7 June. rendezvous.blogs.nytimes.com/2012/06/07/putting-chinese-students-to-the-test (accessed 11 November 2013).

Seidlhofer, Barbara. 2011. Understanding English as a Lingua Franca. Oxford: Oxford University Press.

Seidlhofer, Barbara. 2012. Anglophone-centric attitudes and the globalization of English. Journal of English as a Lingua Franca 1(2). 393-407.

Weiss, Carol. 1983. Ideology, interests, and information. The basis of policy positions. In Daniel Callahan \& Bruce Jennings (eds), Ethics, the social sciences and policy analysis, 213-246. New York: Plenum Press. 


\section{Bionote}

Joseph Lo Bianco is Professor of Language and Literacy Education at the Melbourne Graduate School of Education, University of Melbourne Australia. He serves as elected President of the Tsinghua Asian-Pacific Forum on Translation and Intercultural Studies and Immediate Past President of the Australian Academy of the Humanities (the first educator elected to this role). In 2012 he was appointed Research Director of the United Nations Language and Peace building initiative in Malaysia, Myanmar, Thailand where he is conducting research and policy interventions on multilingual language planning. Since 2011 he has served as research advisor for a European Commission project called LUCIDE (Languages in Urban Communities - Integration and Diversity for Europe), which is conducting research on multilingualism at the municipal level in 12 European cities. Professor Lo Bianco wrote Australia's National Policy on Languages in 1987, the first multilingual national language policy in an English speaking country and was Director of the National Languages and Literacy Institute of Australia until 2002. 


\section{University Library}

\section{- M M I N E R VA A gateway to Melbourne's research publications}

Minerva Access is the Institutional Repository of The University of Melbourne

Author/s:

Lo Bianco, J

Title:

Dialogue between ELF and the field of language policy and planning

Date:

2014-03-01

Citation:

Lo Bianco, J. (2014). Dialogue between ELF and the field of language policy and planning. JOURNAL OF ENGLISH AS A LINGUA FRANCA, 3 (1), pp.197-213. https://doi.org/10.1515/ jelf-2014-0008.

Persistent Link:

http://hdl.handle.net/11343/122072 